\title{
SOME COMPLETELY MONOTONIC FUNCTIONS RELATED TO THE PSI FUNCTION
}

\author{
TOMislaV BuRić AND NEVEN ELEZOVić
}

Abstract. Complete monotonicity properties of some functions involving the psi function are studied and some known results are extended and generalized. Moreover, a necessary and sufficient conditions for some functions to be completely monotonic are presented and proved.

Mathematics subject classification (2010): 33B15, 26D15.

Keywords and phrases: Completely monotonic function, psi function, Laplace transform.

\section{REFERENCES}

[1] M. Abramowitz and I. A. Stegun (EdS), Handbook of Mathematical Functions with Formulas, Graphs, and Mathematical Tables, National Bureau of Standards, Applied Mathematics Series 55, 9th printing, Washington, 1970.

[2] H. Alzer and C. Berg, Some classes of completely monotonic functions, Ann. Acad. Sci. Fenn. Math., 27, 2 (2002), 445-460.

[3] N. BAtiR, On some properties of the gamma function, Expo. Math., 26 (2008), 187-196.

[4] C. BERG, Integral representation of some functions related to the gamma function, Mediterr. J. Math., 1, 4 (2004), 433-439.

[5] C. Berg, H.L. Pedersen, A completely monotone function related to the Gamma function, J. Comput. Appl. Math., 133 (2001), 219-230.

[6] J. Bukac, T. Burić AND N. Elezović, Stirling's formula revisited via some new and classical inequalities, Math. Inequal. Appl., 14, 1 (2011), 235-245.

[7] P. S. Bullen, Handbook of Means and Their Inequalities, Mathematics and its Applications, Volume 560, Kluwer Academic Publishers, Dordrecht/Boston/London, 2003.

[8] J. Bustoz And M. E. H. Ismail, On gamma function inequalities, Math. Comp., 47 (1986), 659667.

[9] CH.-P.CHEN, Inequalities and monotonicity properties for some special functions, J. Math. Inequal., 3, 1 (2009), 79-91.

[10] N. Elezović, C. Giordano And J. PeČarić, The best bounds in Gautschi's inequality, Math. Inequal. Appl., 3 (2000), 239-252.

[11] B.-N. GUO AND F. QI, A property of logarithmically absolutely monotonic functions and the logarithmically complete monotonicity of a power-exponential function, Politehn. Univ. Bucharest Sci. Bull. Ser. A Appl. Math. Phys. 72, 2 (2010), 21-30.

[12] B.-N. GUO AND F. QI, Two new proofs of the complete monotonicity of a function involving the psi function, Bull. Korean Math. Soc., 47, 1 (2010), 103-111; Available online at

URL: http://dx.doi.org/10.4134/BKMS.2010.47.1.103.

[13] F. QI, A class of logarithmically completely monotonic functions and application to the best bounds in the second Gautschi-Kershaw's inequality, J. Comput. Appl. Math., 224, 2 (2009), 538-543; Available online at URL: http://dx.doi.org/10.1016/j .cam.2008.05.030.

[14] F. QI, A class of logarithmically completely monotonic functions and the best bounds in the first Kershaw's double inequality, J. Comput. Appl. Math., 206, 2 (2007), 1007-1014; Available online at URL: http://dx.doi.org/10.1016/j.cam.2006.09.005.

[15] F. QI, A new lower bound in the second Kershaw's double inequality, J. Comput. Appl. Math. (2007), in press; Available online at URL: http://dx.doi.org/10.1016/j.cam.2007.03.016. 
[16] F. QI, Monotonicity results and inequalities for the gamma and incomplete gamma functions, Math. Inequal. Appl., 5, 1 (2002), 61-67.

[17] F. QI, Three classes of logarithmically completely monotonic functions involving gamma and psi functions, Integral Transforms Spec. Funct., 18, 7 (2007), 503-509; Available online at URL: http://dx.doi.org/10.1080/10652460701358976.

[18] F. QI AND CH.-P. CHEN, A complete monotonicity property of the gamma function, J. Math. Anal. Appl., 296, 2 (2004), 603-607.

[19] F. QI AND B.-N. GUO, A class of logarithmically completely monotonic functions and the best bounds in the second Kershaw's double inequality, J. Comput. Appl. Math., 212, 2 (2008), 444-456; Available online at URL: http://dx.doi.org/10.1016/j .cam.2006.12.022.

[20] F. QI AND B.-N. GuO, Wendel's and Gautschi's inequalities: Refinements, extensions, and a class of logarithmically completely monotonic functions, Appl. Math. Comput., 205, 1 (2008), 281-290; Available online at URL: http://dx.doi.org/10.1016/j.amc.2008.07.005.

[21] Feng QI AND BAI-Ni GuO, A class of completely monotonic functions involving divided differences of the psi and tri-gamma functions and some applications, Journal of the Korean Mathematical Society, 48 (2011), in press.

[22] F. QI AND B.-N. GuO, Complete monotonicities of functions involving the gamma and digamma functions, RGMIA Res. Rep. Coll., 7, 1 (2004), Art. 8, 63-72; Available online at URL: http://rgmia.org/v7n1.php.

[23] F. QI, S. GUO AND B.-N. GUO, Complete monotonicity of some functions involving polygamma functions, J. Comput. Appl. Math., 233, 9 (2010), 2149-2160; Available online at URL: http://dx.doi.org/10.1016/j.cam.2009.09.044.

[24] F. QI, B.-N. GuO, AND Ch.-P. Chen, The best bounds in Gautschi-Kershaw inequalities, Math. Inequal. Appl., 9, 3 (2006), 427-436.

[25] F. QI, B.-N. GUO, AND CH.-P. ChEN, Some completely monotonic functions involving the gamma and polygamma functions, J. Aust. Math. Soc., 80 (2006), 81-88.

[26] F. QI, D.-W. NIU, J. CAO, AND SH.-X. CHEN, Four logarithmically completely monotonic functions involving gamma function, J. Korean Math. Soc., 45, 2 (2008), 559-573.

[27] F. QI, W. Li AND B.-N. Guo, Generalizations of a theorem of I. Schur, RGMIA Res. Rep. Coll., 9, 3 (2006), Art. 15; Available online at URL: http://rgmia.org/v9n3 . php.

[28] D. V. Widder, The Laplace Transform, Princeton University Press, Princeton, 1946. 